\title{
Does obesity impact treatment outcome for prostate cancer patients treated with radiotherapy: the weighted debate
}

\begin{abstract}
Background: There is conflicting evidence in the literature for the impact of obesity on treatment outcome for prostate cancer patients treated with radiotherapy. The first aim of this study is to identify if obesity negatively impacts on treatment outcome for obese prostate cancer patients treated with radiation therapy. The second aim of this study is to compare the treatment modalities used to treat obese and non-obese prostate cancer patients to establish if there is a benefit in treatment outcome when using particular treatment modalities for BMI groups.
\end{abstract}

Materials and Methods: A database search using PubMed, Embase, The Cochrane Library and Science direct was performed to search articles published 2003-2013. Articles were selected based on relevancy, content and quality.

Results: Eighteen articles and 25,397 patients were included in this review collectively. Radiation therapy treatment methods included brachytherapy, 3-dimentional conformal radiotherapy, intensity modulated radiotherapy and tomotherapy. Studies using conformal external beam radiotherapy techniques, image guided radiotherapy, hypofractionated regimes or brachytherapy show little or no impact of obesity on treatment outcome or toxicity. Studies using non-conformal techniques, lower total doses and poor image guided radiotherapy (IGRT) show inferior treatment outcome and increased toxicity for obese prostate cancer patients treated with radiation therapy.

Conclusion: Greater BMI is associated with decreased overall survival. However, the negative impact of obesity on radiation induced toxicity, biochemical relapse and prostate cancer specific mortality may be prevented if treatment includes brachytherapy, IGRT, hypofractionated regimes and conformal radiotherapy techniques. Future studies are needed to establish individualised treatment protocol for obese patients.

Keywords: obesity, BMI, treatment outcome, overall survival, biochemical recurrence, disease free survival, prostate cancer specific mortality, side effects, toxicity
Volume I Issue 4 - 2014

Hilary Smyth
Trinity College Dublin, Ireland

Correspondence: Hilary Smyth, Sunny Meadow, Sea Road, Newcastle, Co. Wicklow, Ireland, Tel 851558698, Emailsmythhj@tcd.ie

Received: November 26, 2014 | Published: December 20, 2014
Abbreviations: BMI, body mass index; RT, radiation therapy; EBRT, external beam radiation therapy; BT, brachytherapy; IGRT, image guided radiation therapy; BCR, biochemical recurrence; OS, overall survival; ADT, androgen deprivation therapy; IMRT, intensity modulated radiation therapy; PCS, physical component scale; EPIC, expanded prostate cancer index composite scoring system; SF-12, short form health survey; PCSS, prostate cancer specific survival; PCSM, prostate cancer specific mortality; CI, confidence interval; PSA, prostate specific antigen; CT, computed tomography; HR, hazard ratio; RR, relative risk; ASTRO, American society of therapeutic radiation oncology; LR, left-right; $\mathrm{AP}$, anterior-posterior; SI, superior-inferior; PCA, prostate cancer

\section{Introduction}

The incidence of obesity worldwide has been increasing concurrently with prostate cancer (PCa) diagnosis among men. ${ }^{1}$ Obesity alone substantially impacts public health.,3 Obesity is linked with a number of cancers including $\mathrm{PCa}^{4-6} \mathrm{PCa}$ is the sixth most common cause of cancer related death in men worldwide. ${ }^{1}$ The confusing relationship between obesity and $\mathrm{PCa}$ has been a topic of ongoing research. This debate discusses the impact of obesity of treatment outcome and radiation induced toxicity for $\mathrm{PCa}$ patients treated with radiation therapy. Obesity has shown to increase risk of
PCa death. ${ }^{1,5,7-10}$ A recent meta-analysis and systematic review showed that a $5 \mathrm{~kg} / \mathrm{m}^{2}$ BMI increase was associated with a $15 \%$ higher risk of biochemical relapse after radiation therapy and a $5 \mathrm{~kg} / \mathrm{m}^{2}$ increase in BMI was associated with $15 \%$ higher risk of dying of $\mathrm{PCa} .{ }^{11}$ MacInnis et al., ${ }^{12}$ found that BMI was associated with a $12 \%$ higher risk of advanced PCa for each $5 \mathrm{~kg} / \mathrm{m}^{2}$ increase.

Obese PCa patients have shown to present with aggressive disease and less commonly to present with non-aggressive disease. ${ }^{13,14}$ One current hypothesis is that obesity lowers the risk of non-aggressive $\mathrm{PCa}$ while increasing the risk of aggressive $\mathrm{PCa} .{ }^{15,16}$ This relationship, associated co-morbidities and technical difficulties when treating obese patients can influence treatment outcome greatly when using any modality. Studies have shown the negative impact of obesity on treatment outcome after radical prostatectomy (RP) ${ }^{17,18}$ and androgen deprivation therapy (ADT). ${ }^{11,19,20}$ While it is clear that obesity negatively influences RP and ADT, the evidence in relation to radiation therapy is contradictory. PSA prostate specific antigen can be used as a tumour marker for PCa detection and in conjunction with grade and stage can predict the course and outcome of treatment for the patient. There is a current need to understand the relationship between BMI and treatment failure following radiation therapy to establish BMIs predictive value. PSA recurrence is used as a surrogate for treatment failure in this and previous studies. 
A previous meta-analysis ${ }^{11}$ found no association between obesity and biochemical recurrence (BCR) in brachytherapy. However, there was increased risk of BCR when using external beam radiation therapy (EBRT). This raises the question, is brachytherapy more suited to obese patients than external beam therapy?

Treatment outcome can be considered under the following headings; disease free survival, biochemical recurrence, prostate cancer specific mortality (PCSM) and overall survival (OS). This study compares these conflicting results and will debate the following arguments; obesity negatively impacts on treatment outcome after radiation therapy and obesity increases toxicity for prostate cancer patients treated with radiation therapy. For PCa patients, dose volume constraints of organs at risk can be treatment dose limiting. Occurrence of radiation induced toxicity and side effects can decrease patients' quality of life. The rectum, small bowel, bladder and penile bulb are the organs at risk (OAR). ${ }^{21-24}$ Standardised toxicity scoring systems can be used to analyse and compare toxicity of radiation therapy.

\section{Aims and objectives}

This aim of this debate is to establish if obesity negatively influences treatment outcome or toxicity for prostate patients treated with radiation therapy. It compares contrasting literature to identify evidence for and against the arguments. The long term goal of this study is to highlight if there is a need for a change in the management of obese patients to ensure equal treatment benefit for PCa patients of all BMI categories.

I. The first aim of this study is to identify if obesity negatively impacts on treatment outcome for obese prostate cancer patients treated with radiation therapy. This will be done through two objectives. Firstly by comparing treatment outcome of obese and non-obese prostate cancer patients after radiation therapy. Biochemical relapse, disease free survival, overall survival and prostate cancer specific death are the outcomes compared between obese and non-obese cohorts. Secondly, by comparing radiation induced toxicity data between obese and non-obese prostate cancer patients treated with radiation therapy. Toxicity affecting patient quality of life, hormonal, gastrointestinal, genitourinary and sexual function is compared between cohorts.

II. The second aim of this study is to compare the treatment modalities used to treat obese and non-obese prostate cancer patients to establish if there is a benefit in treatment outcome when using particular treatment modalities for BMI groups. The first objective to complete this aim is to establish if there is a trend in treatment modality used for particular BMI groups. The second objective to is to establish if treatment outcome is improved or worsened when particular treatment modalities are used for particular BMI groups.

\section{Materials and methods}

Search strategy for identification of studies. A database search using Pubmed, Embase, The Cochrane Library and Science Direct was performed to search articles published 2003-2013 using advanced search filters and the search terms. Articles were selected based on relevancy, quality and content. The references were searched for relevant articles and analysed to ensure they met the inclusion criteria. If only an abstract was available, the full study was searched for through UCD library or TCD inter library loan.

\section{Inclusion criteria}

Worldwide study groups of any ethnicity and geographical location are included. Patient's cohorts of different BMI levels treated with external beam radiation therapy and/or brachytherapy for $\mathrm{PCa}$ are included for comparison. The participant population can include surgical or hormone adjuvant therapies as studies with radiation therapy as monotherapy are few. Patient BMI category must be clearly documented. All studies must include obese and non-obese BMI categories.

\section{Exclusion criteria}

If more than one article was published on the same study population the study with the larger sample size and/or longer followup period was used if the same outcome was documented for both papers. Palliative and metastatic patient groups at time of primary treatment were excluded. Articles not using BMI to measure obesity were excluded. Abstract only articles were excluded. Studies not published in the English language were excluded.

\section{Search terms}

Search terms were formed by combining keywords (Table1).

\section{Type of studies}

Published studies that met all inclusion and exclusion criteria were included. Retrospective and prospective studies comparing treatment outcome and treatment related toxicity were included. The studies must compare obese and non-obese patients in relation to treatment outcome or toxicity, using any radiation therapy treatment modality. The outcomes for each BMI group can therefore be compared in relation to each modality used.

\section{Type of participants}

Participants include $\mathrm{PCa}$ patients who are obese at time of treatment. Different BMI categories ranging from healthy/normal to obese should be included as a means of control group. Any disease stage could be included up to palliative patients or patients with metastases at time of first treatment. Radical and salvage radiation therapy (RT) patients are included.

\section{Type of interventions}

BMI was used as a surrogate for obesity. BMI is a universal inter-study comparison tool. BMI does not account for body mass composition or the distribution of adipose tissue, but is as a surrogate of obesity used to compare studies. The WHO BMI classifications are used (Table 2).

\section{Outcome measures}

Treatment outcome after radiation therapy can be analysed in terms of biochemical recurrence, disease free survival, overall survival and prostate cancer specific mortality. Biochemical recurrence is a detectable PSA level in the blood following treatment. ASTRO $^{11}$ and Phoenix ${ }^{12}$ defined biochemical failure reported to allow easier comparison with other series in the literature. The American Society of Therapeutic Radiation Oncology (ASTRO) defines PSA failure as three consecutively rising PSA nadir levels. The Phoenix definition is $2.0 \mathrm{ng} / \mathrm{ml}$ plus the nadir point. Patients with a stable but higher PSA level than $>0.5 \mathrm{ng} / \mathrm{ml}$ should remain disease free. PSA levels can fluctuate during the follow-up period. Toxicity of 
the genitourinary system, gastrointestinal system, vitality, hormonal function and erectile function is analysed. Incidence and grade of toxicity and difference in quality of life parameters can be measured by standardised toxicity scoring systems. The Radiation Therapy Oncology Group (RTOG) scoring system, Late Effects Normal Tissue Task Force (LENT)-Subjective, Objective, Management, Analytic (SOMA) scale, Common Terminology Criteria for Adverse Events (CTCAE) EORTC scales, the Short Form Health Survey (SF-12) ${ }^{25}$ and the Expanded Prostate Cancer Index Composite (EPIC) scoring system ${ }^{26}$ were used to assess the level of RT induced toxicity and health related patient quality of life. Vaizey faecal incontinence scores were used. ${ }^{27}$

Table I Sensitive dependency of human mental function on prefrontal cortex influence

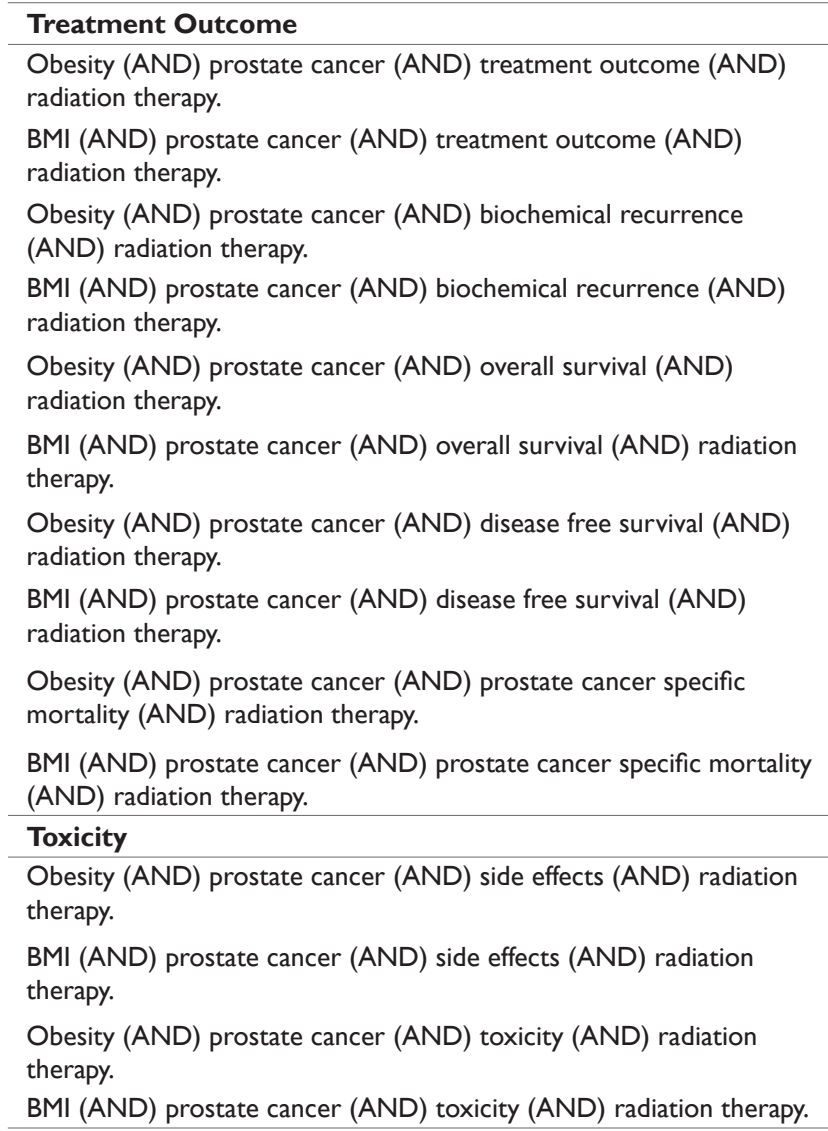

Table 2 WHO BMI classification

\begin{tabular}{ll}
\hline Category & BMI range $\mathbf{~ k g} / \mathbf{m}^{2}$ \\
\hline Very severely underweight & $\leq 14.9$ \\
Severely underweight & $15.0-15.9$ \\
Underweight & $16.0-18.4$ \\
Normal & $18.5-24.9$ \\
Overweight & $25-29.9$ \\
Obese I (Moderately obese) & $30-34.9$ \\
Obese II (Severely obese) & $35-39.9$ \\
Obese III (Very severely obese) & $40+$ \\
\hline
\end{tabular}

\section{Data collection and analysis}

After the database searches, articles were excluded based on title, abstract, content, quality, inclusion and exclusion criteria. Following the collection of eligible studies, a data collection form was filled out for each study. There are two data collection forms, one for treatment outcome (Appendix A) and one for toxicity (Appendix B).

\section{Statistical analysis}

The studies used univariate and multivariate Cox proportional hazards regression analyses to determine whether BMI significantly predicted treatment outcomes or toxicity. Kaplan Meier survival curves were used to show the relationship between BMI and survival over time and incidence of toxicity over time. Log rank tests were used to compare survival curves. Hazard ratios (HR) and confidence intervals (CI) were presented in some studies. P-value $<0.05$ is considered statistically significant. Randomised controlled trials were appraised using the method described by Jaddad AR et al. ${ }^{28}$ (Appendix C). Prospective and retrospective cohort studies were appraised using the Critical Appraisal Skills Programme (CASP) Cohort Study Checklist 31.05 .13 (Appendix D). ${ }^{29}$

\section{Results}

The literature search found 232 articles through the databases and references searched, of which 18 were included in this review (Figure 1). From the 18 studies, 25,397 patients were included collectively. All included studies were published between 2005 and 2013. RT treatment methods included low dose rate (LDR) brachytherapy, 3 dimensional conformal radiation therapy (3D-CRT), intensity modulated radiation therapy (IMRT) and tomotherapy.

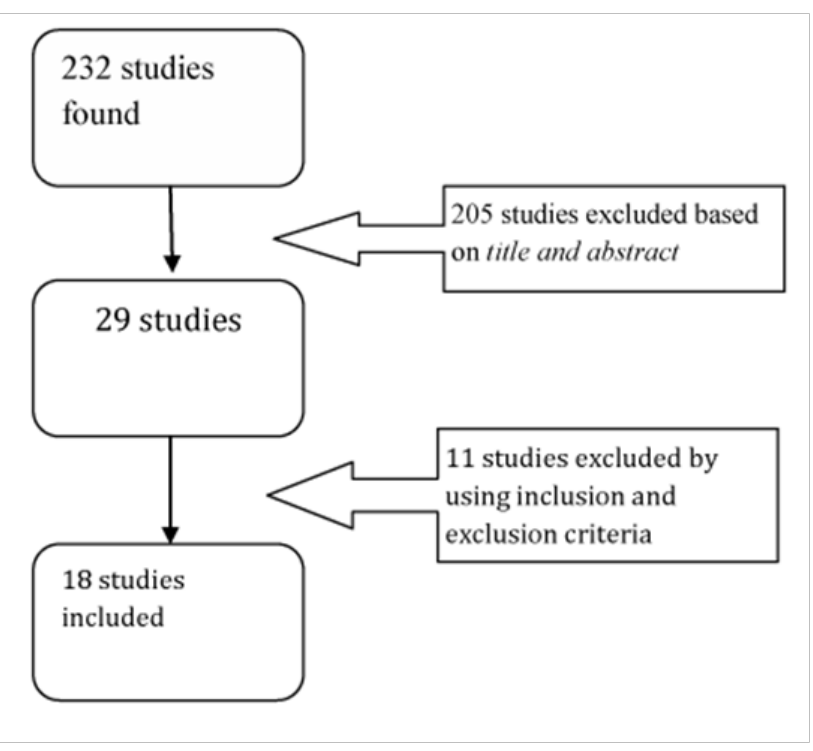

Figure I Flowchart of search method.

\section{Treatment outcome}

Seven studies found support the argument that obesity negatively impacts treatment outcome for prostate cancer patients treated with radiotherapy. Five studies are against this argument.

\section{Toxicity}

Three studies support the argument that obesity increases toxicity for PCa patients treated with radiotherapy. Two studies are against this argument. The table of included studies presents the individual study results and details Table 3 included as supplementary. See (Table 4 \& 5) for the table of arguments and supportive studies. 
Table 4 Table of arguments

\begin{tabular}{|c|c|c|}
\hline & For & Against \\
\hline $\begin{array}{l}\text { Argument I: Obesity negatively impacts } \\
\text { treatment outcome for prostate cancer patients } \\
\text { treated with radiation therapy. }\end{array}$ & $\begin{array}{l}\text { Obesity negatively impacts treatment outcome } \\
\text { for prostate cancer patients treated with radiation } \\
\text { therapy. }\end{array}$ & $\begin{array}{l}\text { Obesity has no impact on treatment outcome } \\
\text { for prostate cancer patients treated with } \\
\text { radiation therapy. }\end{array}$ \\
\hline $\begin{array}{l}\text { Argument } 2 \text { : Obesity increases radiation } \\
\text { induced toxicity for prostate cancer patients } \\
\text { treated with radiation therapy. }\end{array}$ & $\begin{array}{l}\text { Obesity increases radiation induced toxicity for } \\
\text { prostate cancer patients treated with radiation } \\
\text { therapy. }\end{array}$ & $\begin{array}{l}\text { Obesity does not increase radiation induced } \\
\text { toxicity for prostate cancer patients treated with } \\
\text { radiation therapy. }\end{array}$ \\
\hline \multicolumn{3}{|c|}{$\begin{array}{l}\text { Argument I: Obesity negatively impacts treatment outcome for prostate cancer patients } \\
\text { treated with radiation therapy }\end{array}$} \\
\hline For & Against & \\
\hline Stroup SP et al., ${ }^{30}$ & Van Roermund JGH et al., ${ }^{53}$ & \\
\hline Eftstathiou JA et al., ${ }^{31}$ & Zilli T et al., ${ }^{57}$ & \\
\hline Efstathiou JA et al., ${ }^{31}$ & Davies BJ et al., ${ }^{5} 8$ & \\
\hline Gong Z et al., ${ }^{7}$ & Geinitz $\mathrm{H}$ et al.,49 & \\
\hline King CR et al., ${ }^{32}$ & Merrick GS et al. ${ }^{50}$ & \\
\hline Palma D et al., ${ }^{46}$ & Merrick GS et al., ${ }^{51}$ & \\
\hline \multicolumn{3}{|l|}{ Strom SS et al., ${ }^{47}$} \\
\hline \multicolumn{3}{|c|}{$\begin{array}{l}\text { Argument 2: Obesity increases radiation induced toxicity for prostate cancer patients } \\
\text { treated with radiation therapy }\end{array}$} \\
\hline For & Against & \\
\hline Dieperink KB et al. ${ }^{59}$ & Patil $\mathrm{N}$ et al..$^{34}$ & \\
\hline Sanda MG et al. ${ }^{60}$ & Elliott SP et al..$^{35}$ & \\
\hline Thomas RJ et al. ${ }^{33}$ & & \\
\hline
\end{tabular}

Table $5 \mathrm{BMI}$ association with poorest treatment outcome and toxicity

\begin{tabular}{|c|c|c|c|c|}
\hline Author and year & Patients & BMI Reported & Poorest Treatment Outcome at BMI & Highest Toxicity at BMI \\
\hline \multirow{4}{*}{ King et al.,. ${ }^{32}$} & \multirow{4}{*}{$N=90$} & $\mathrm{n}=17<25 \mathrm{~kg} / \mathrm{m}^{2}$ & \multirow{4}{*}{$\mathrm{BMI} \geq 35 \mathrm{~kg} / \mathrm{m}^{2}$} & \multirow{4}{*}{-} \\
\hline & & $\mathrm{n}=52 \geq 25-<30 \mathrm{~kg} / \mathrm{m}^{2}$ & & \\
\hline & & $\mathrm{n}=17 \geq 30-<35 \mathrm{~kg} / \mathrm{m}^{2}$ & & \\
\hline & & $\mathrm{n}=4 \geq 35 \mathrm{~kg} / \mathrm{m}^{2}$ & & \\
\hline Efstathiou et al., ${ }^{31}$ & $N=99$ & Median baseline $\mathrm{BMI}=27.4 \mathrm{~kg} / \mathrm{m} 2(24.8-30.7)$ & BMI $\geq$ median $\left(27.4 \mathrm{~kg} / \mathrm{m}^{2}\right)$ & - \\
\hline \multirow{4}{*}{ Davies et al., ${ }^{58}$} & \multirow{4}{*}{$N=7274$} & $\mathrm{n}=2091<25 \mathrm{~kg} / \mathrm{m}^{2}$ & \multirow{4}{*}{$\mathrm{BMI} \geq 30-<35 \mathrm{~kg} / \mathrm{m}^{2}$} & \multirow{4}{*}{-} \\
\hline & & $\mathrm{n}=3640 \geq 25-<30 \mathrm{~kg} / \mathrm{m}^{2}$ & & \\
\hline & & $\mathrm{n}=1193 \geq 30-<35 \mathrm{~kg} / \mathrm{m}^{2}$ & & \\
\hline & & $\mathrm{n}=350 \geq 35 \mathrm{~kg} / \mathrm{m}^{2}$ & & \\
\hline \multirow{3}{*}{ Palma et al.. ${ }^{46}$} & \multirow{3}{*}{$N=706$} & $\mathrm{n}=195<25 \mathrm{~kg} / \mathrm{m}^{2}$ & \multirow{3}{*}{$\mathrm{BMI}>35 \mathrm{~kg} / \mathrm{m}^{2}$} & \multirow{3}{*}{-} \\
\hline & & $\mathrm{n}=358 \geq 25-<30 \mathrm{~kg} / \mathrm{m}^{2}$ & & \\
\hline & & $\mathrm{n}=153 \geq 30+\mathrm{kg} / \mathrm{m}^{2}$ & & \\
\hline \multirow{4}{*}{ Stroup et al., ${ }^{30}$} & \multirow{4}{*}{$N=1,868$} & $\mathrm{n}=659<25 \mathrm{~kg} / \mathrm{m}^{2}$ & \multirow{4}{*}{$\mathrm{BMI} \geq 30 \mathrm{~kg} / \mathrm{m}^{2}$} & \multirow{4}{*}{$\mathrm{BMI} \geq 30 \mathrm{~kg} / \mathrm{m}^{2}$} \\
\hline & & $\mathrm{n}=810 \geq 25-<30 \mathrm{~kg} / \mathrm{m}^{2}$ & & \\
\hline & & $\mathrm{n}=288 \geq 30-<35 \mathrm{~kg} / \mathrm{m}^{2}$ & & \\
\hline & & $\mathrm{n}=1 \mathrm{I} I \geq 35 \mathrm{~kg} / \mathrm{m}^{2}$ & & \\
\hline \multirow{3}{*}{ Efstathiou et al., ${ }^{31}$} & \multirow{3}{*}{$N=788$} & $\mathrm{n}=24 \mathrm{l}<25 \mathrm{~kg} / \mathrm{m}^{2}$ & \multirow{3}{*}{$\mathrm{BMI} \geq 25 \mathrm{~kg} / \mathrm{m}^{2}$} & \multirow{3}{*}{.-} \\
\hline & & $\mathrm{n}=402 \geq 25-<30 \mathrm{~kg} / \mathrm{m}^{2}$ & & \\
\hline & & $\mathrm{n}=145 \geq 30 \mathrm{~kg} / \mathrm{m}^{2}$ & & \\
\hline \multirow{4}{*}{ Strom et al., ${ }^{47}$} & \multirow{4}{*}{$N=873$} & $\mathrm{n}=234<25 \mathrm{~kg} / \mathrm{m}^{2}$ & \multirow{4}{*}{$\mathrm{BMI} \geq 30 \mathrm{~kg} / \mathrm{m}^{2}$} & \multirow{4}{*}{-} \\
\hline & & $\mathrm{n}=434 \geq 25-<30 \mathrm{~kg} / \mathrm{m}^{2}$ & & \\
\hline & & $\mathrm{n}=157 \geq 30-<35 \mathrm{~kg} / \mathrm{m}^{2}$ & & \\
\hline & & $\mathrm{n}=48 \geq 35 \mathrm{~kg} / \mathrm{m}^{2}$ & & \\
\hline \multirow{3}{*}{ Gong et al., ${ }^{7}$} & \multirow{3}{*}{$N=752$} & $\mathrm{n}=257<25 \mathrm{~kg} / \mathrm{m}^{2}$ & \multirow{3}{*}{$\mathrm{BMI} \geq 30 \mathrm{~kg} / \mathrm{m} 2$} & \multirow{3}{*}{-} \\
\hline & & $\mathrm{n}=367 \geq 25-<30 \mathrm{~kg} / \mathrm{m}^{2}$ & & \\
\hline & & $n=128 \geq 30+$ & & \\
\hline
\end{tabular}


Table Continued...

\begin{tabular}{|c|c|c|c|c|}
\hline Author and year & Patients & BMI Reported & Poorest Treatment Outcome at BMI & Highest Toxicity at BMI \\
\hline & & $\mathrm{n}=177<25 \mathrm{~kg} / \mathrm{m}^{2}$ & & \\
\hline \multirow[t]{3}{*}{ Geinitz et al., ${ }^{49}$} & \multirow[t]{3}{*}{$N=564$} & $\mathrm{n}=302 \geq 25-<30 \mathrm{~kg} / \mathrm{m}^{2}$ & \multirow[t]{3}{*}{$\mathrm{BMI} \geq 25-<30 \mathrm{~kg} / \mathrm{m}^{2}$} & \multirow[t]{3}{*}{-} \\
\hline & & $\mathrm{n}=85 \geq 30+$ & & \\
\hline & & $\mathrm{n}=167<25 \mathrm{~kg} / \mathrm{m}^{2}$ & & \\
\hline \multirow{4}{*}{ Merrick et al., ${ }^{50}$} & \multirow{4}{*}{$N=686$} & $\mathrm{n}=348 \geq 25-<30 \mathrm{~kg} / \mathrm{m}^{2}$ & \multirow{4}{*}{$\mathrm{BMI} \geq 30-<35 \mathrm{~kg} / \mathrm{m}^{2}$} & \multirow{4}{*}{-} \\
\hline & & $\mathrm{n}=135 \geq 30-<35 \mathrm{~kg} / \mathrm{m}^{2}$ & & \\
\hline & & $\mathrm{n}=36 \geq 35 \mathrm{~kg} / \mathrm{m}^{2}$ & & \\
\hline & & $\mathrm{n}=258<25 \mathrm{~kg} / \mathrm{m}^{2}$ & & \\
\hline \multirow{4}{*}{ Merrick et al., ${ }^{41}$} & \multirow{3}{*}{$N=1093$} & $\mathrm{n}=547 \geq 25-<30 \mathrm{~kg} / \mathrm{m}^{2}$ & \multirow{3}{*}{$\mathrm{BMI}<25 \mathrm{~kg} / \mathrm{m}^{2}$} & \multirow{3}{*}{-} \\
\hline & & $\mathrm{n}=214 \geq 30-<35 \mathrm{~kg} / \mathrm{m}^{2}$ & & \\
\hline & & $\mathrm{n}=74 \geq 35 \mathrm{~kg} / \mathrm{m}^{2}$ & & \\
\hline & \multirow{4}{*}{$N=1530$} & $\mathrm{n}=617<25 \mathrm{~kg} / \mathrm{m}^{2}$ & \multirow{4}{*}{$\mathrm{BMI}<25 \mathrm{~kg} / \mathrm{m}^{2}$} & \multirow{4}{*}{-} \\
\hline \multirow{3}{*}{$\begin{array}{l}\text { Van Roermund et } \\
\text { al., } 53\end{array}$} & & $\mathrm{n}=754 \geq 25-<30 \mathrm{~kg} / \mathrm{m}^{2}$ & & \\
\hline & & $n=159 \geq 30+$ & & \\
\hline & & $\mathrm{n}=27<25 \mathrm{~kg} / \mathrm{m}^{2}$ & & \\
\hline \multirow[t]{2}{*}{ Zilli et al.., ${ }^{57}$} & \multirow[t]{2}{*}{$N=112$} & $\mathrm{n}=55 \geq 25-<30 \mathrm{~kg} / \mathrm{m}^{2}$ & \multirow[t]{2}{*}{$\mathrm{BMI} \geq 30 \mathrm{~kg} / \mathrm{m}^{2}$} & \multirow[t]{2}{*}{-} \\
\hline & & $\mathrm{n}=30 \geq 30+\mathrm{kg} / \mathrm{m}^{2}$ & & \\
\hline Dieperink et al., ${ }^{59}$ & $N=317$ & Mean BMI 28.2 (27.7-28.7) & - & $\mathrm{BMI} \geq 30 \mathrm{~kg} / \mathrm{m}^{2}$ \\
\hline \multirow{3}{*}{ Sanda et al.., ${ }^{60}$} & \multirow{2}{*}{$N=|20|$} & Brachytherapy Mean BMI $28.5 \pm 4.7$ kg/m² & \multirow{2}{*}{-} & \multirow{2}{*}{$\mathrm{BMI} \geq 35 \mathrm{~kg} / \mathrm{m}^{2}$} \\
\hline & & EBRT Mean BMI $28.6 \pm 5.4 \mathrm{~kg} / \mathrm{m}^{2}$ & & \\
\hline & & $\mathrm{n}=4<18.5 \mathrm{~kg} / \mathrm{m}^{2}$ & & \\
\hline \multirow{3}{*}{ Thomas et al., } & \multirow{3}{*}{$N=440$} & $\mathrm{n}=157 \quad 18.5-24.9 \mathrm{~kg} / \mathrm{m}^{2}$ & \multirow{3}{*}{-} & \multirow{3}{*}{$\mathrm{BMI} \geq 30 \mathrm{~kg} / \mathrm{m}^{2}$} \\
\hline & & $\mathrm{n}=16725-29.9 \mathrm{~kg} / \mathrm{m}^{2}$ & & \\
\hline & & $\mathrm{n}=1 \mathrm{I} \mathrm{Ikg} / \mathrm{m} 2 \geq 30 \mathrm{~kg} / \mathrm{m}^{2}$ & & \\
\hline \multirow[t]{2}{*}{ Patil et al., ${ }^{34}$} & \multirow[t]{2}{*}{$N=407$} & Mean BMI $27.8 \mathrm{~kg} / \mathrm{m}^{2} \pm 4.2$ & \multirow[t]{2}{*}{-} & \multirow[t]{2}{*}{$\mathrm{BMI}>27.8 \mathrm{~kg} / \mathrm{m}^{2}$} \\
\hline & & $\mathrm{n}=1328<25 \mathrm{~kg} / \mathrm{m}^{2}$ & & \\
\hline Flligtt et al 35 & $N=6597$ & $\mathrm{n}=2418 \geq 25-<30 \mathrm{~kg} / \mathrm{m}^{2}$ & & RMI $>25<<30 \mathrm{k} / \mathrm{m}$ \\
\hline Linvech es al., & 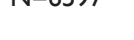 & $\mathrm{n}=1036 \geq 30-<35 \mathrm{~kg} / \mathrm{m}^{2}$ & 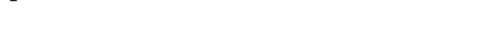 & Dा 11:-20- \\
\hline
\end{tabular}

\section{Discussion}

There is contradicting evidence for and against each argument There are seven studies supporting the argument that obesity negatively impacts treatment outcome for prostate cancer patients treated with radiation therapy. Worse outcome may be due to inherent technical difficulties and the underlying tumour biology and aggressive disease. Obesity related biological mechanisms and detection bias were not the main topic of causation in the current debate. However, these are mentioned in all seven studies. Stroup et al., ${ }^{30}$ shows that obese patients treated with EBRT and ADT have significantly higher rates of PSA recurrence over time than non obese patients. Eftstathiou et al., ${ }^{31}$ found that men with a BMI $\geq$ median*** had double the risk of PSA recurrence at 5 years than men with lower BMIs. Gong et al., ${ }^{7}$ shows that there is no difference between modality used to predict the outcome of increased metastases occurrence and prostate cancer death for obese patients.

A study by King et al., ${ }^{32}$ is only weakly suggestive that obesity is associated with a greater risk of biochemical relapse for patients treated with salvage RT after RP. The statistical weakness lessens the strength of this argument. The association of obesity with relapse was of only borderline significance after exclusion of the 4 severely obese patients from the analysis. These 4 patients on average had several disadvantageous factors which could include extra capsular extension
ECE, positive seminal vesicles, positive margins, lower RT dose, and greater pre-RT PSA level.

Palma et al., ${ }^{33}$ found BMI predicted reduced time to biochemical relapse, reduced disease free survival and decreased OS. Similarly, Strom et al., ${ }^{34}$ found increased body mass index significantly predicted BCR and is a predictor of disease progression. Efstathiou et al., ${ }^{35}$ found that a greater baseline BMI is independently associated with higher cancer-specific mortality in men with locally advanced PCa. Overweight and obese patients were 1.8 times more likely to die of prostate cancer than those with normal weight. There are six studies supporting the argument that obesity does not impact on treatment outcome for PCa patients treated with radiation therapy. Geinitz et al., ${ }^{36}$ found that BMI had no significant impact on BCR, prostate cancer specific survival or overall survival. Suggests with increasing use of IGRT and accurate dose delivery, there will be minimal impact from BMI on treatment outcome. Two brachytherapy studies led by Merrick et al. ${ }^{37,38}$ found that BMI had no statistically significant influence on biochemical progression-free survival, cause specific survival or biochemical progression free survival. This outcome is repeated in a brachytherapy study one year later. ${ }^{39}$ Cardiovascular or pulmonary disease and second malignancies outweighed prostate cancer as competing causes of death in the obese patient groups. To add controversy to this argument there was still a non-statistically significant decrease in overall survival of $3.5 \%$ for obese and $1 \%$ for 
severely obese cohorts and there was a trend for better biochemical outcome in the severely obese cohort. The decrease in overall survival may be attributable to the co-morbidities of obesity and not the interaction of obesity and prostate cancer.

Van Roermund et al., ${ }^{40}$ concluded that BMI had no significant association of risk for BCR, CSS and OS with obesity and had no prognostic impact when using permanent prostate seed brachytherapy as the primary treatment method. It is imperative to point out that it is low risk patients treated with brachytherapy and it is patients from any risk category treated with EBRT. From the studies included, the brachytherapy studies showing favourable outcome have the advantage of patients with low risk patients and therefore better prognosis when compared to the higher risk patients used in the EBRT studies. Obese PCa patients are more likely to have brachytherapy and less likely to have surgical intervention as primary treatment. ${ }^{41}$ This may be due to the increased risk of positive surgical margins in the obese patient, particularly on the apical margins ${ }^{42}$ and the technical feasibility and demonstrated favourable treatment outcome for obese patients treated with brachytherapy. ${ }^{43}$

Zilli et al., ${ }^{44}$ suggests that the observed increase in biochemical failure in obese patients in previous EBRT studies may be more closely related to inaccurate dose delivery than to a more aggressive disease. This suggests that abdominal fat distribution and other anthropometric measures of obesity are neither associated with adverse pathologic features in patients with intermediate-risk prostate cancer nor with a higher risk of biochemical failure when modern IGRT techniques are used. If outcomes following IGRT are poorer, then obesity itself would be the adverse factor. The study also noted the correlation between increasing BMI and increasing prostate size. While the study supports the argument that obesity does not affect treatment outcome, it highlights the point that a larger prostate can make brachytherapy and EBRT technically more difficult to plan and deliver, supporting the argument that obesity negatively impacts treatment outcome. Davies et al. ${ }^{45}$ studied the impact of obesity on all treatment modalities and found that while higher BMI negatively impacted overall survival, no difference in prostate cancer specific mortality were observed between BMI groups. There are three studies supporting the argument that obesity increases radiation induced toxicity for PCa patients treated with radiation therapy. The data from Dieperink et al. ${ }^{46}$ shows that obesity is significantly associated with a lower quality of life $(\mathrm{QoL})$ regarding incontinence and PCS after radiotherapy, severe obesity was a negative predictor for moderateto-severe problems in the EPIC urinary incontinence, and in the hormonal domain. Severe obesity reduced the mean PCS score and increased risk of moderate-to-severe problems with SF-12 vitality, consistent with the findings of Sanda et al. ${ }^{47}$

Sanda et al. ${ }^{47}$ found that obesity worsened vitality and hormonal function after brachytherapy or EBRT. However, Sanda defined obese as having a $\mathrm{BMI} \geq 35 \mathrm{~kg} / \mathrm{m}^{2}$ unlike the majority of other included studies where $\geq 30 \mathrm{~kg} / \mathrm{m}^{2}$ is considered obese. A recent study by Thomas et al. ${ }^{48}$ found there was a significant association between men with a higher BMI and greater rectal (Vaizey faecal incontinence scores) symptoms scores, rectal bleeding and nocturia. However, the study didn't record baseline scores before treatment. Without this method of control, bias is introduced. All three of these studies must note that post-treatment toxicity is dependent on pre-treatment, baseline functional scoring which is generally worse in overweight and obese patients. There are two studies against the argument that obesity has no impact on toxicity for $\mathrm{PCa}$ patients treated with radiation therapy. A dosimetric brachytherapy study by Patil et al. ${ }^{49}$ showed that men with a lower BMI (non-obese) received a higher rectal wall dose compared to those with higher BMI in the obese and severely obese categories. This did not, however, translate into greater rectal toxicity but interestingly shows a protective influence of higher BMI and more fatty tissue in the prostate rectum interface with rectal dose. This further presents brachytherapy as the most suited radiotherapy treatment for obese patients. Elliott et al., ${ }^{50}$ analysed urethral stricture risk among treatment modalities and weight categories and concluded that BMI was only significantly indicative of stricture after RP not EBRT or BT.

The results are difficult to interpret for treatment outcome and toxicity because a large proportion of patients received supplemental therapies that could have masked differences in outcome. The contradicting studies might be explained by the fact that BMI is not a reliable estimate of the impact of obesity on PCa patients. ${ }^{51}$ Abdominal fat and visceral adiposity may more effectively predict aggressive disease biology than BMI. ${ }^{52-54}$ Obese men have shown to have higher grade and larger tumours generally which can cause treatment failure ${ }^{55}$ and this may be the cause of inferior outcome for obese patients as they may require more aggressive treatment. However, their treatment plan is equivalent to their healthy BMI counterparts. Historical studies have demonstrated that treatment outcome is negatively affected by BMI. More recent EBRT studies and brachytherapy based studies observed no significant treatment outcome change. This may be due to set-up error and prostate displacement in combination with less accurate and less precise treatment techniques used up to 10 years ago. Wong et al., ${ }^{56-58}$ demonstrates the increased prostate movement with rising BMI. The correlation between obesity and the deviation of the target from the planned position indicates that without image-guided radiation therapy, the target volume may not receive the intended tumourocidal dose for patients who are moderate to severely obese due to geographical miss or change in the planned dose distribution. This may explain the higher recurrence rate and incidence of side effects with conventional EBRT. Patients with large BMI values (i.e., BMI >35) tended to have greater prostate shift in the LR direction $(\sigma \mathrm{LR}=8.9 \mathrm{~mm}$ for the severely obese group) compared with those in the other three groups (range, $3.0-3.8 \mathrm{~mm}$ ). Similar to the finding of Millender et al., ${ }^{59}$ this indicates that the LR shift of the prostate is significantly influenced by the patient's body parameters, whereas the shifts in the other two directions Anterior-Posterior(AP) and SuperiorInferior (SI) are not extensively altered.

Thompson et al., ${ }^{60,61}$ found patients with a higher BMI have less intrafraction displacement of the prostate in the SI direction compared with patients with a lower BMI. This has implications for individualised treatment margins for future prostate cancer patients undergoing image-guided radiotherapy. Research has shown that once the patients set-up error had been corrected, prostate displacement is equally unstable in obese patients than in non-obese patients in the $\mathrm{AP}$ and left-right (LR) directions. ${ }^{59-62}$ The deposition of periprostatic fat and visceral adiposity may explain the selective movement of the prostate in the LR and AP direction and stabilisation in the SI direction. The use of IGRT, fiducial markers and conformal treatment techniques with individualised margins may reduce the difference in outcome for obese and non-obese patients. Unstable skin marks are not sufficient for set-up accuracy alone. Brachytherapy does not use external skin markers and eliminates the potential error of prostate shift from the planned position. The favourable outcome for brachytherapy in obese patients may be explained by the closed transperineal approach, steep dose gradient outside the target volume and real time prostate imaging. 
It is observed that obese patients have larger prostate volumes ${ }^{63,64}$ which can be problematic when planning brachytherapy. It may necessitate lowering the prostate volume using hormonal therapy as planning a larger prostate volume for brachytherapy is more technically challenging and can result in an inferior dose distribution when compared to smaller prostate sizes. The prostate gland size should preferably be small as a large prostate frequently overlaps with the pubic arch, which interferes with needle placement ${ }^{65}$ Additionally, large prostates require more seeds to achieve the prescribed dose, which results in an increased risk of urinary morbidity. Patients with large prostates should be prescribed a combination of androgen blockade with luteinizing hormone releasing hormone analogue and anti-androgen to reduce the prostate size before implantation. The separation of the patient is larger than the average patient so higher beam energies are needed. The availability of higher beam energies is more common in the United States but is not routine in Ireland or Europe. Creating the desired dose distribution for these patients can be difficult in comparison with a patient of a healthy BMI and smaller patient separation when using 3D-CRT. Conversely, IMRT is not affected as lower energies are used.

This study recommends the use of IGRT in the treatment of prostate cancer patients of all BMI categories. One limitation when using IGRT for obese patients is poor image quality for larger patient separations. Tumour assessment, image verification and planning images can all suffer. ${ }^{66}$ In addition, the table weight and CT aperture size must be adequate to accommodate the obese patient to begin with. Increasing BMI produces higher X-ray attenuation and scatter with lower image contrast. ${ }^{66,67}$ This can increase exposure time and increase risk of motion artefacts.

Ultrasound (US) imaging can also suffer in quality. The thickness of subcutaneous fat and the sound-attenuating properties of fat present challenges. Sound attenuation increases with fat thickness and transducer frequency, meaning the higher the frequency, the greater the attenuation. ${ }^{68}$ This therefore gives poorer image quality in obese patients with high levels of subcutaneous fat. Zilli et al., ${ }^{44}$ employed US based IGRT for obese patients and found that they still had favourable outcomes. For MRI magnetic resonance imaging, image quality is least affected by obesity however the MRI bore size can be a limiting factor as this can be smaller than the CT aperture size ${ }^{66}{ }^{\text {There }}$ has been a recent push towards opening aperture sizes in MRI and $\mathrm{CT}$ machines as the levels of obesity rise. The results and arguments from this study are supported by a past systematic review and metaanalysis which studied the relationship between BMI, PCSM and BCR. ${ }^{11}$ Among patients treated with radiation therapy, no association between BMI and biochemical recurrence was detected in patients receiving brachytherapy. However BMI was associated with BCR in patients treated with EBRT.

\section{Limitations and future work}

The limitations of this study include the lack of prospective or randomised control trials and small patient numbers in higher BMI categories. Retrospective studies were used which can introduce bias. There is a need for a future study that is prospective, using modern, conformal techniques, representative of techniques used to date with IGRT and a large patient pool with a sufficiently long follow-up period. Improved standardised toxicity scoring systems are required to facilitate comparisons between studies.

Studies using radiation therapy exclusively for treatment would be beneficial, as inclusion of adjuvant therapies can bias the results. PSA failure is often used as a surrogate end point in studies that do not have enough follow-up or events to report the outcomes of metastases and death. Whether PSA failure is a good surrogate is open to debate. This is particularly relevant for obese men given that they are subject to PSA hemodilution and hormonal abnormalities, both of which bias PSA score $[69,70]$. PSA failure may not be a valid surrogate in obese men. Furthermore, studies using self-reported BMI and toxicity scores introduced bias to the results.

The timing of BMI measurement may be significant in its fluctuation over time, particularly for patients receiving ADT where weight gain can be a side effect. Other limitations include lack of control for lifelong vs adult onset obesity which may confound the results. Weight loss strategy and treatment technique consensus are further areas for study.

\section{Conclusion}

Studies using conformal EBRT techniques with IGRT and dose escalation and brachytherapy studies do not show obesity as a negative influence on treatment outcome or toxicity. Studies without IGRT and less conformal EBRT treatment techniques with lower total doses show inferior treatment outcome and increased side effects for obese patients. Prostate displacement and set-up error leading to incorrect dose delivery could account for inferior treatment outcome and increased toxicity. It is clear that in certain situations, obesity can affect these outcomes after radiation. However, further study is warranted to establish if this can be prevented by using IGRT, internal immobilisation techniques or brachytherapy. It is clear that obesity has an impact on treatment outcome and toxicity for PCa patients treated with RT. We now need continued follow-up data to determine the best individualised RT treatment for obese patients.

\section{Acknowledgments}

I would like to thank those who helped me along my way to completing this research project. I would like to thank Laura Mullaney for her support, encouragement and guidance. I want to thank my friends and family for the support and kind words of encouragement throughout my studies.

\section{Conflicts of interest}

Author declares there are no conflicts of interest.

\section{References}

1. Center MM, Jemal A, Lortet-Tieulent J, et al. International Variation in Prostate Cancer Incidence and Mortality Rates. Eur Urol. 2012;61(6):1079-1092.

2. Haslam DW, James WP. Obesity. Lancet. 2005;366(9492):1197-1209.

3. Fowke JH, Motley S, Dai Q, et al. Association between biomarkers of obesity and risk of high-grade prostatic intraepithelial neoplasia and prostate cancer--evidence of effect modification by prostate size. Cancer Lett. 2013;328(2):345-352.

4. Calle EE, Kaaks R. Overweight, obesity and cancer: epidemiological evidence and proposed mechanisms. Nat Rev Cancer. 2004;4(8):579-591.

5. Calle EE, Rodriguez C, Walker-Thurmond K, et al. Overweight, obesity, and mortality from cancer in a prospectively studied cohort of U.S. adults. $N$ Engl J Med. 2003;348(17):1625-1638.

6. Calle EE, Thun MJ. Obesity and cancer. Oncogene. 2004;23(38):6365-6378.

7. Gong Z, Agalliu I, Lin DW, et al. Obesity is associated with increased risks of prostate cancer metastasis and death after initial cancer diagnosis in middle-aged men. Cancer. 2007;109(6):1192-1202. 
8. Rodriguez C, Patel AV, Calle EE, et al. Body mass index, height, and prostate cancer mortality in two large cohorts of adult men in the United States. Cancer Epidemiol Biomarkers Prev. 2001;10(4):345-353.

9. Ma J, Li H, Giovannucci E, et al. Prediagnostic body-mass index, plasma C-peptide concentration, and prostate cancer-specific mortality in men with prostate cancer: a long-term survival analysis. Lancet Oncol. 2008;9(11):1039-1047.

10. Wright ME, Chang SC, Schatzkin A, et al. Prospective study of adiposity and weight change in relation to prostate cancer incidence and mortality Cancer. 2007;109(4):675-684.

11. Cao Y, Ma J. Body mass index, prostate cancer-specific mortality, and biochemical recurrence: A systematic review and meta-analysis. Cancer Prev Res (Phila). 2011;4(4):486-501.

12. MacInnis RJ, English DR. Body size and composition and prostate cancer risk: systematic review and meta-regression analysis. Cancer Causes Control. 2006;17(8):989-1003.

13. Buschemeyer WC, Freedland SJ. Obesity and Prostate Cancer: Epidemiology and Clinical Implications. Eur Urol. 2007;52(2):331-343.

14. Allott EH, Masko EM, Freedland SJ. Obesity and Prostate Cancer: Weighing the Evidence. Eur Urol. 2013;63(5):800-809.

15. Freedland SJ, Giovannucci E, Platz EA. Are Findings from Studies of Obesity and Prostate Cancer Really in Conflict? Cancer Causes Control. 2006;17(1):5-9.

16. Gong Z, Neuhouser ML, Goodman PJ, et al. Obesity, diabetes, and risk of prostate cancer: results from the prostate cancer prevention trial. Cancer Epidemiol Biomarkers Prev. 2006;15(10):1977-1983.

17. Campeggi A, Xylinas E, Ploussard G, et al. Impact of body mass index on perioperative morbidity, oncological, and functional outcomes after extraperitoneal laparoscopic radical prostatectomy. Urology. 2012;80(3):576-584.

18. Ho T, Gerber L, Aronson WJ, et al. Obesity, Prostate-Specific Antigen Nadir, and Biochemical Recurrence After Radical Prostatectomy: Biology or Technique? Results from the SEARCH Database. Eur Urol. 2012;62(5):910-916.

19. Keto CJ, Aronson WJ, Terris MK, et al. Obesity is associated with castration-resistant disease and metastasis in men treated with androgen deprivation therapy after radical prostatectomy: results from the SEARCH database. BJU Int. 2012;110(4):492-498.

20. Smith MR. Obesity and sex steroids during gonadotropin-releasing hormone agonist treatment for prostate cancer. Clin Cancer Res. 2007;13(1):241-245.

21. Kavanagh BD, Pan CC, Dawson LA, et al. Radiation dose-volume effects in the stomach and small bowel. Int J Radiat Oncol Biol Phys. 2010;76(3 Suppl):S101-S107.

22. Viswanathan AN, Yorke ED, Marks LB, et al. Radiation dose-volume effects of the urinary bladder. Int J Radiat Oncol Biol Phys. 2010;76(3 Suppl):S116-S122.

23. Michalski JM, Gay H, Jackson A, et al. Radiation dose-volume effects in radiation-induced rectal injury. Int J Radiat Oncol Biol Phys. 2010;76(3 Suppl):S123-S129

24. Roach M, Nam J, Gagliardi G, et al. Radiation dose-volume effects and the penile bulb. Int J Radiat Oncol Biol Phys. 2010;76(3 Suppl):S130 S134.

25. Ware J, Kosinski M, Keller SD. A 12-Item Short-Form Health Survey: construction of scales and preliminary tests of reliability and validity. Med Care. 1996;34(3):220-233.

26. Wei JT, Dunn RL, Litwin MS, et al. Development and validation of the expanded prostate cancer index composite (EPIC) for comprehensive assessment of health-related quality of life in men with prostate cancer. Urology. 2000;56(6):899-905.
27. Vaizey CJ, Carapeti E, Cahill JA, et al. Prospective comparison of faecal incontinence grading systems. Gut. 1999;44(1):77-80.

28. Jadad AR, Moore RA, Carroll D, et al. Assessing the quality of reports of randomized clinical trials: is blinding necessary? Control Clin Trials. 1996;17(1):1-12.

29. CASP at the Public Health Resource Unit Appraisal tools. Public Health Resource Unit, Oxford; 2007.

30. Stroup SP, Cullen J, Auge BK, et al. Effect of obesity on prostate-specific antigen recurrence after radiation therapy for localized prostate cancer as measured by the 2006 Radiation Therapy Oncology Group-American Society for Therapeutic Radiation and Oncology (RTOG-ASTRO) Phoenix consensus definition. Cancer. 2007;110(5):1003-1009.

31. Efstathiou JA, Chen MH, Renshaw AA, et al. Influence of body mass index on prostate-specific antigen failure after androgen suppression and radiation therapy for localized prostate cancer. Cancer. 2007;109(8):1493-1498.

32. King CR, Spiotto MT, Kapp DS. Obesity and Risk of Biochemical Failure for Patients Receiving Salvage Radiotherapy after Prostatectomy. Int J Radiat Oncol Biol Phys. 2009;73(4):1017-1022.

33. Thomas RJ, Holm M, Williams M, et al. Lifestyle Factors Correlate with the Risk of Late Pelvic Symptoms after Prostatic Radiotherapy. Clin Oncol (R Coll Radiol). 2013;25(4):246-251.

34. Patil N, Crook J, Saibishkumar EP, et al. The effect of obesity on rectal dosimetry after permanent prostate brachytherapy. Brachytherapy. 2009;8(2):218-222.

35. Elliott SP, Meng MV, Elkin EP, et al. Incidence of Urethral Stricture after Primary Treatment for Prostate Cancer: Data From CaPSURE. J Urol. 2007;178(2):529-534.

36. Zilli T, Chagnon M, Van Nguyen $\mathrm{T}$, et al. Influence of abdominal adiposity, waist circumference, and body mass index on clinical and pathologic findings in patients treated with radiotherapy for localized prostate cancer. Cancer. 2010;116(24):5650-5658.

37. Wallstrom P, Bjartell A, Gullberg B, et al. A prospective Swedish study on body size, body composition, diabetes, and prostate cancer risk. $\mathrm{Br} \mathrm{J}$ Cancer. 2009;100(11):1799-1805.

38. Pischon T, Boeing $\mathrm{H}$, Weikert $\mathrm{S}$, et al. Body size and risk of prostate cancer in the European prospective investigation into cancer and nutrition. Cancer Epidemiol Biomarkers Prev. 2008;17(11):3252-3261.

39. Von Hafe P, Pina F, Perez A, et al. Visceral fat accumulation as a risk factor for prostate cancer. Obes Res. 2004;12(12):1930-1935.

40. Freedland SJ, Banez LL, Sun LL, et al. Obese men have higher-grade and larger tumours: an analysis of the duke prostate center database. Prostate Cancer Prostatic Dis. 2009;12(3):259-263.

41. Wong JR, Gao Z, Selvaggi P, et al. Comparison of Inter fractional Prostate Motion among Normal, Overweight, and Obese Patient Groups. International Journal of Radiation Oncology Biology Physics. 2007;69(3):S740.

42. Wong JR, Gao Z, Merrick S, et al. Potential for Higher Treatment Failure in Obese Patients: Correlation of Elevated Body Mass Index and Increased Daily Prostate Deviations from the Radiation Beam Isocenters in an Analysis of 1,465 Computed Tomographic Images. Int J Radiat Oncol Biol Phys. 2009;75(1):49-55.

43. Wong JR, Gao Z, Uematsu M, et al. Inter fractional Prostate Shifts: Review of 1870 Computed Tomography (CT) Scans Obtained During Image-Guided Radiotherapy Using CT-on-Rails for the Treatment of Prostate Cancer. Int J Radiat Oncol Biol Phys. 2008;72(5):1396-1401.

44. Millender LE, Aubin M, Pouliot J, et al. Daily electronic portal imaging for morbidly obese men undergoing radiotherapy for localized prostate cancer. Int J Radiat Oncol Biol Phys. 2004;59(1):6-10. 
45. Thompson A et al. Body mass index in prostate cancer patients treated with external beam radiotherapy demonstrates no statistical association with prostate shift. Journal of Medical Imaging and Radiation Oncology. 2009;53:A87.

46. Palma D, Pickles T, Tyldesley S. Obesity as a predictor of biochemical recurrence and survival after radiation therapy for prostate cancer. $B J U$ Int. 2007;100(2):315-319.

47. Strom SS, Kamat AM, Gruschkus SK, et al. Influence of obesity on biochemical and clinical failure after external-beam radiotherapy for localized prostate cancer. Cancer. 2006;107(3):631-639.

48. Efstathiou JA, Bae K, Shipley WU, et al. Obesity and mortality in men with locally advanced prostate cancer: analysis of RTOG 85-31. Cancer. 2007;110(12):2691-2699.

49. Geinitz H, Thamm R, Mueller $\mathrm{T}$, et al. Impact of Body Mass Index on Outcomes after Conformal Radiotherapy in Patients with Prostate Cancer. Int J Radiat Oncol Biol Phys. 2011;81(1):16-22.

50. Merrick GS, Butler WM, Wallner KE, et al. Influence of body mass index on biochemical outcome after permanent prostate brachytherapy. Urology. 2005;65(1):95-100.

51. Merrick GS, Galbreath RW, Butler WM, et al. Obesity is not predictive of overall survival following permanent prostate brachytherapy. Am J Clin Oncol. 2007;30(6):588-596.

52. Efstathiou JA, Skowronski RY, Coen JJ, et al. Body Mass Index and Prostate-Specific Antigen Failure Following Brachytherapy for Localized Prostate Cancer. Int J Radiat Oncol Biol Phys. 2008;71(5):1302-1308.

53. Van Roermund JGH, Hinnen KA, Battermann JJ, et al. Body mas index is not a prognostic marker for prostate-specific antigen failure and survival in Dutch men treated with brachytherapy. BJU Int. 2010;105(1):42-48.

54. Davies BJ, Walsh TJ, Ross PL, et al. Effect of BMI on primary treatment of prostate cancer. Urology. 2008;72(2):406-411.

55. Jayachandran J, Aronson WJ, Terris MK, et al. Obesity and positive surgical margins by anatomic location after radical prostatectomy: Results from the shared equal access regional cancer hospital database. BJU Int. 2008;102(8):964-968.

56. Rockhill J, Wallner K, Hoffman C, et al. Prostate brachytherapy in obese patients. Brachytherapy. 2002;1(1):54-60.

57. Zilli T, Nguyen TV, Bahary JP, et al. Prognostic impact of abdominal adiposity, waist circumference and body mass index in patients with intermediate-risk prostate cancer treated with radiotherapy. Int $J$ Obes (Lond). 2011;35(11):1421-1426.
58. Davies BJ, Smaldone MC, Sadetsky N, et al. The Impact of Obesity on Overall and Cancer Specific Survival in Men With Prostate Cancer. $J$ Urol. 2009;182(1):112-117.

59. Dieperink KB, Hansen S, Wagner L, et al. Living alone, obesity and smoking: important factors for quality of life after radiotherapy and androgen deprivation therapy for prostate cancer. Acta Oncol. 2012;51(6):722-729.

60. Sanda MG, Dunn RL, Michalski J, et al. Quality of life and satisfaction with outcome among prostate-cancer survivors. $N$ Engl J Med. 2008;358(12):1250-1261.

61. Thompson AL, Gill S, Thomas J, et al. In Pursuit of Individualised Margins for Prostate Cancer Patients Undergoing Image-guided Radiotherapy: The Effect of Body Mass Index on Intrafraction Prostate Motion. Clin Oncol (R Coll Radiol). 2011;23(7):449-453.

62. Logsdon MD, Bareng JK, Olson L, et al. Favorable IMRT Experience Treating Obese Prostate Cancer Patients in the Prone Position using Electromagnetic Tracking and a "Belly Board". International Journal of Radiation Oncology Biology Physics. 2009;75(3): S609-S610.

63. Muller RL, Gerber L, Moreira DM, et al. Obesity Is Associated with Increased Prostate Growth and Attenuated Prostate Volume Reduction by Dutasteride. Eur Urol. 2013;63(6):1115-1121.

64. Freedland SJ, Platz EA, Presti JC, et al. Obesity, Serum Prostate Specific Antigen and Prostate Size: Implications for Prostate Cancer Detection. $J$ Urol. 2006;175(2):500-504.

65. Park DS. Current status of brachytherapy for prostate cancer. Korean Journal of Urology. 2012;53(11):743-749.

66. Carucci LR. Imaging obese patients: problems and solutions. Abdom Imaging. 2013;38(4):630-646.

67. Hijazi H, Magne N, Levy A, et al. Features of cancer management in obese patients. Crit Rev Oncol Hematol. 2013;85(2):193-205.

68. Hangiandreou NJ. AAPM/RSNA physics tutorial for residents. Topics in US: B-mode US: basic concepts and new technology. Radiographics. 2003;23(4):1019-1033.

69. Banez LL, Hamilton RJ, Partin AW, et al. Obesity-related plasma hemodilution and PSA concentration among men with prostate cancer. JAMA. 2007;298(19):2275-2280.

70. Kaaks RA, Lukanova, Sommersberg B. Plasma androgens, IGF-1, body size, and prostate cancer risk: a synthetic review. Prostate Cancer Prostatic Dis. 2000;3(3):157-172. 